\title{
Experimental research of cutting forces during microgrinding
}

\author{
Aleksandr Dyakonov ${ }^{1}$, and Anastasia Gorodkova ${ }^{1, *}$ \\ ${ }^{1}$ South Ural State University, 454000 Chelyabinsk, Russian Federation
}

\begin{abstract}
In high-speed and heat-stressed processes, the cutting force is a determining parameter of surface quality. The existing studies of the cutting force in microgrinding are experimental and their results are valid for a narrow range of the processed material. The paper describes the experimental study of strength when microgrinding complex alloy steel. The obtained results allow to expand the field of use of micro-grinding technology applied to metal materials.
\end{abstract}

\section{Introduction}

Micro-grinding is a method of processing precise micro-products from metallic and nonmetallic materials [1-2]. The need for the development of this technology for processing micro-parts is observed in many fields, for example, for processing interfacing surfaces of the compact brake mechanisms used on autonomous generating stations [3], processing the gimbal's parts in aerospace industry (fig. 1a), in medical field - tools for microsurgery (fig. 1b), processing lens in optics etc [4].

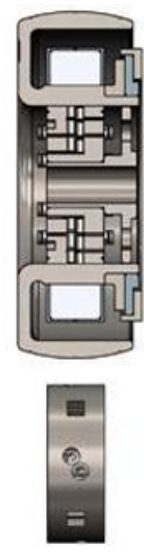

a

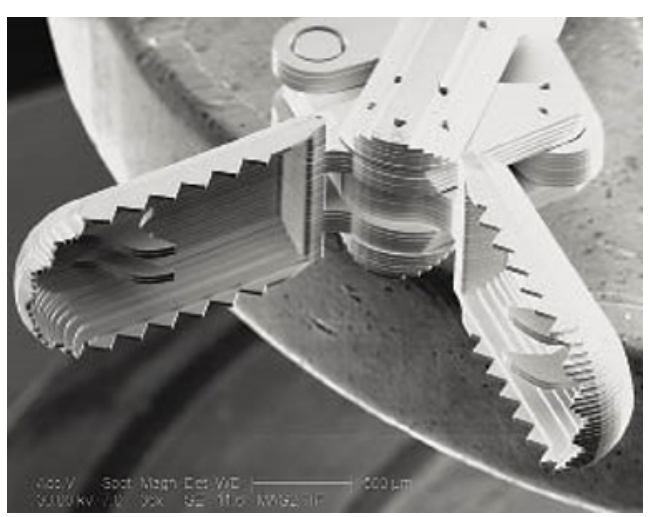

b

Fig. 1. Sample parts, a - gimbal, b - kelectome

\footnotetext{
*Corresponding author: gor-nastya@mail.ru
} 
Currently, the South Ural state University is working to study the process of microgrinding details of precise navigation systems made of complex alloyed steel. Due to the fact that microgrinding is a fairly new technology, its adaptation into the current production is hampered by the lack of recommendations for the design of the operation. Most of the existing studies are experimental and consider certain processed materials and processing conditions. To simplify the process of applying the technology in works, it is necessary to simplify the procedure for selecting the optimal cutting conditions by developing a comprehensive simulation model of the process, which will take into account such important components of the cutting process as the cutting force and temperature in the cutting zone.

The main feature of the micro-grinding process is the dimension of the cutting zone [56]. The depth of cut is a few micrometers, and the overall dimensions of the part usually are a few millimeters. In this regard, there are a number of differences from the traditional grinding, which limits the use of existing models of grinding to predict the output parameters of the cutting process [7-8]. In high-speed and heat-stressed processes, the force

and temperature in the cutting zone, respectively, are the determining parameters of the quality and accuracy of processing.

In order to predict the temperature in the cutting zone and its further regulation by changing the cutting conditions, the authors developed a thermophysical model of microgrinding, based on the numerical implementation of the solution of the second boundary value problem for the heat equation by the finite difference method [9]. The model is numerically implemented in the bundled software "Calculation of the workpiece temperature during micro-grinding on CNC machines" patent № 2017619909, which allows to determine the temperature of the workpiece in the process of microgrinding, depending on the following input parameters: workpiece material, feed, depth of cut, machining time, etc. Temperature prediction using the calculation method avoids the appearance of various defects, such as bulk, cauterization on the treated surface at the design stage of the operation.

Due to the dimensional effect in microgrinding, the microstructure of the material greatly affects the cutting force as a result of the stress change. Zhao M., Ji X., Li B., Liang, S.Y. studied the changes in the stress resulting from changes in the crystallographic orientation during micro-grinding and the resulting cutting force during the processing of a single grain [10]. In their work, the authors described the approbation process of the developed model in microgrinding of ceramics. In the paper "Prediction of grinding force in microgrinding of ceramic materials by cohesive zone-based finite element method", the authors present a force model for microgrinding, developed on the basis of the finite element method [11]. The processed material is ceramics. Sun Y., Liu H., Zheng Q. in the paper " Experimental investigation of grinding force in microgrinding of ceramic materials using small grinding tool " describes the experimental study of cutting forces in microgrinding of ceramic materials [12]. In his work L. Yan, Ya-dong Ya S. G., Huang Z., Qiang L. describe the process of approbation the force model when microgrinding glass [13].

Analysis of the researches devoted to the study of force in microgrinding, showed that most of them are devoted to the study of features of processing of non-metallic materials: glass, ceramics. The obtained dependences and force models may have significant differences in their application for predicting cutting conditions during micro-grinding of metal products. The aim of this work is experimental studies of the cutting force in microgrinding steel for further develop of the microgrinding force model or the introduction of correction factors in the existing models when proving their adequacy is applicable to the change of the processed material. 


\section{Materials and methods}

A series of experiments was carried out for determination the value of the cutting force during micro-grinding. EMCO Mill 300 equipped with the high-speed pneumatic spindle HTS1501S (fig. 2) was used as an experimental set up. Spindle rotational speed is 150000 rpm. Grinding head type AW was used as a cutting tool (fig.3). The material of the cutting part - abrasive stone.

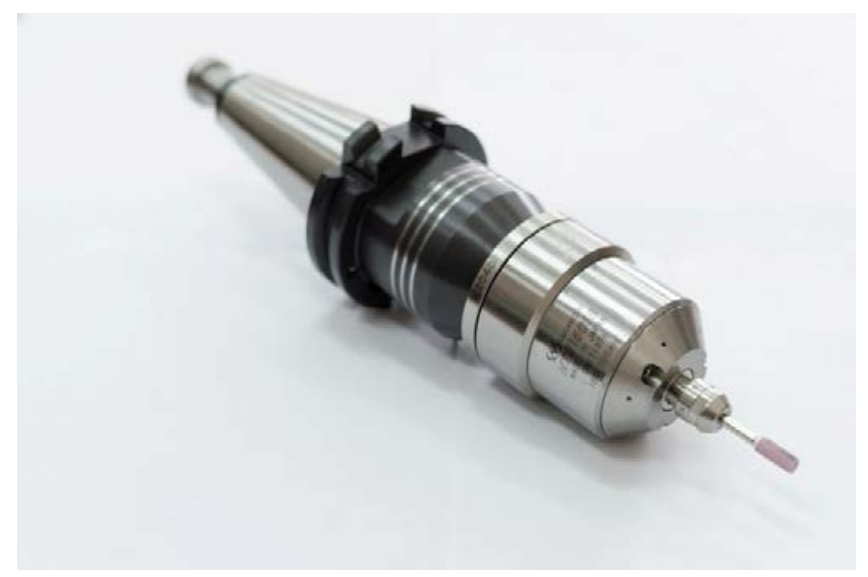

Fig. 2. High-speed pneumatic spindle HTS1501S

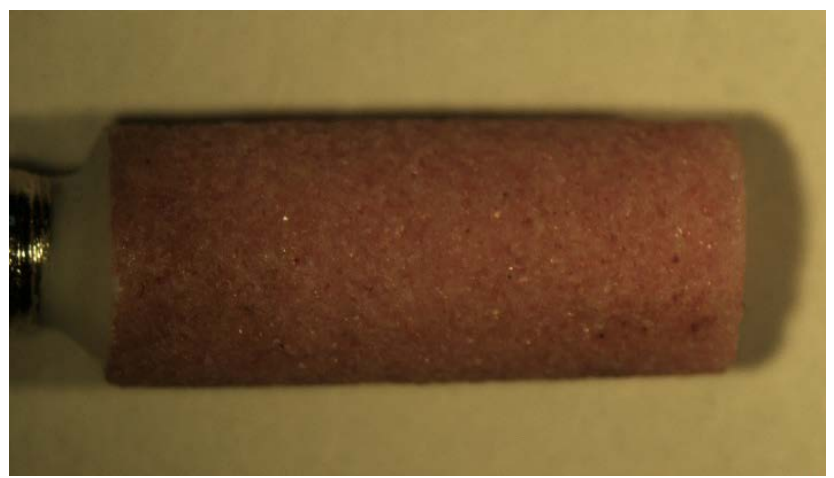

Fig. 3.Cutting tool with 30x magnification

40 channels were microgrinding in the workpiece of steel 40KXHM. This steel was chosen because at the moment we consider the possibility of using micro-grinding technology for the processing of parts from this material. The force measurement was carried out during processing with the help of the Kistler dynamometer.

\section{Results and discussion}

Cutting force values were obtained during the microgrinding experiments. The analysis of the obtained results showed that when the feed rate increases, the tangential cutting force is increase significantly. The thrust force and the feed force increase slightly. Figure 4 shows 
the graph of the tangential cutting force from the feed during the microgrinding the channel depth of $0,1 \mathrm{~mm}$.

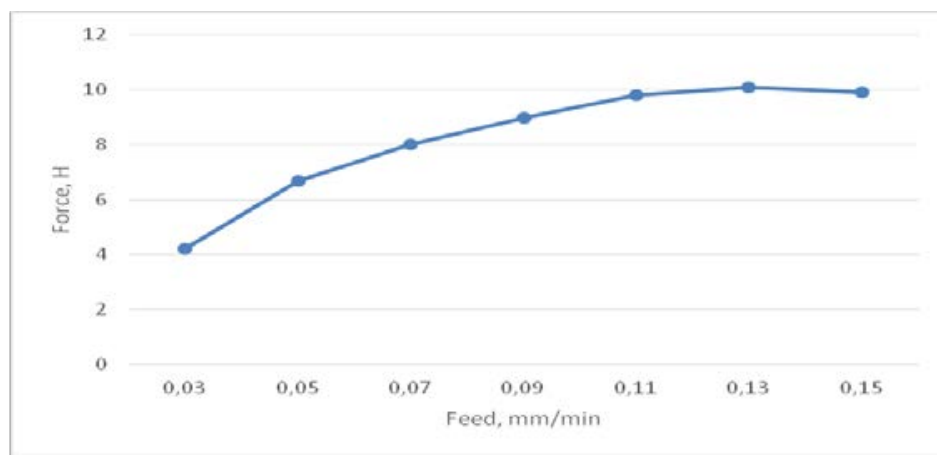

Fig. 4. Dependence of tangential cutting force on feed speed

Figure 5 shows cutting force graphs for processing the channel depth of $0,1 \mathrm{~mm}$ when feed was $0,05 \mathrm{~mm} / \mathrm{min}, 0,09 \mathrm{~mm} / \mathrm{min}$ and $0,15 \mathrm{~mm} / \mathrm{min}$ respectively. The graphs show that Fz increase from 4,2 $\mathrm{H}$ to $9,9 \mathrm{H}, \mathrm{Fx}-$ from $2,3 \mathrm{H}$ to $4,3 \mathrm{H}$, Fy change in the range 3,3-3,9 $\mathrm{H}$ depending on the feed value. Cutting force almost not vary during the processing of the one channel.

We find out metal sphere on the processed surface of the channel depth $0,2 \mathrm{~mm}$ at a research with the help of the microscope with 50x magnification (fig.6).

Appearance such metal spheres is consequences of high temperature in the cutting zone in the conventional grinding. At the moment we carry out a more detailed study the causes of this defect as for conventional grinding as for microgrinding. Also we are going to calculate the temperature in the cutting zone with the help of the bundled software "Calculation of the workpiece temperature during micro-grinding on CNC machines".

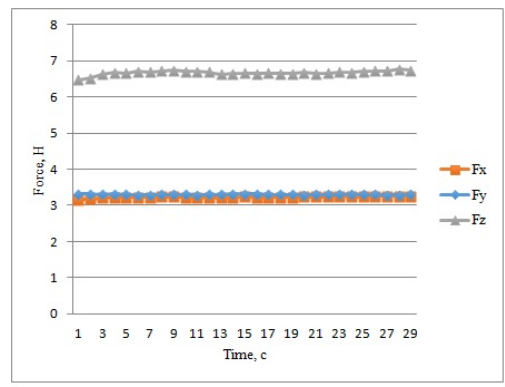

a

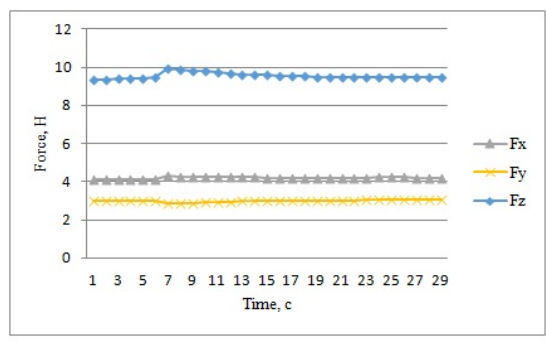

b

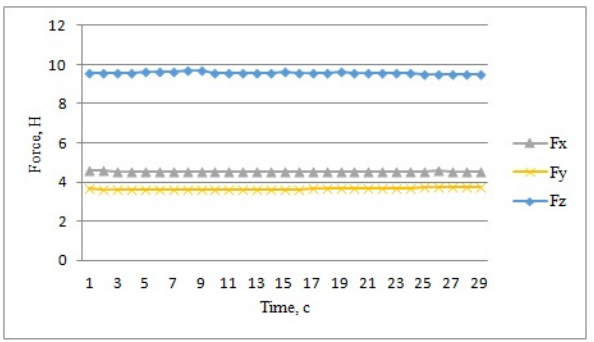

c

Fig. 5. The graphics of the cutting force for different feed rates, a- $0,05 \mathrm{~mm} / \mathrm{min} ; \mathrm{b}-0,09 \mathrm{~mm} / \mathrm{min}$; c $-0,15 \mathrm{~mm} / \mathrm{min}$ 


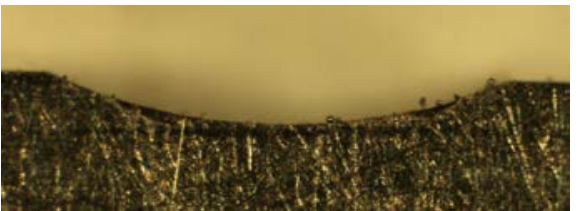

a

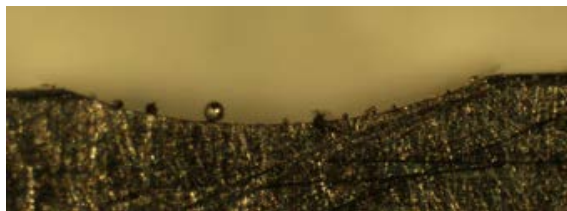

б

Fig. 6. Metal spheres on the processed surface, $a-t=0,2 \mathrm{~mm}, S=0,05 \mathrm{~mm} / \mathrm{min} ; \mathrm{b}-\mathrm{t}=0,2 \mathrm{~mm}, \mathrm{~S}=0,13$ $\mathrm{mm} / \mathrm{min}$

\section{Conclusion}

Dependences of the cutting force from grinding depth and feed speed were obtained during the experiments. These dependences allow to check the validity of the developed models for nonmetallic materials as applied to metallic materials, to determine the coefficients or completely change the model in case of the inconsistency experimental and calculation data.

Also we determined that there is the high temperature which is characterized the appearance of the metal spheres in the cutting zone in the certain cutting conditions. At the moment we carry out the causes and methods for escape such defects.

The work was supported by the grant of the President of the Russian Federation MD932.2017.8.

\section{References}

1. J. L. Liow, J. of Clean. Prod. 17, 662-667 (2009)

2. A.Pratap, K. Patra, A.A., Dyakonov, Proc. Eng. 150, 969-974 (2016)

3. E.A. Sirotkin, E.V. Solomin, S.A. Gandza, I.M. Kirpichnikova, J. of Phys.: Conf. Ser. 944, 012109 (2018)

4. S.Yakunin, J. Heitz, Appl. Opt. 48, 6172-6177 (2009)

5. A. Aramcharoen, P.T. Mativeng, Prec. Eng. 33, 402-407 (2009)

6. M.Dickerhof, MINAM Position Paper, Chap. 2, (2011)

7. A.A. Dyakonov, L.V.Shipulin, Rus. Eng. Res. 36, 63-66 (2016)

8. I.V. Shmidt, A.A. Dyakonov, Lect. Not. in Eng. and Comp. Sc. 2, 914-917 (2014)

9. A.A. Dyakonov, A.V. Herreinstein, A.E. Gorodkova, Rus. Eng. Res. 37, 647-650 (2017)

10. M. Zhao, X. Ji, B. Li, S.Y. Liang, Int. J. of Adv. Manuf. Tech., 90, 3347-3355 (2017)

11. J. Feng, P. Chen, J. Ni Int. J. of Adv. Manuf. Tech. 68, 1039-1053 (2013)

12. Y. Sun, H. Liu, Q. Zheng, Key Eng. Mat. 522, 236-239 (2012)

13. L. Yin, G.Ya-dong, S. Yao, Z. Huan, L.Qiang, Int. J. of Adv. Manuf. Tech. 94, 24012417 (2018) 